\title{
MULTILEVEL BUCK CONVERTER FOR AUTOMOTIVE ELECTRICAL LOAD
}

\author{
E. T. Yabefa ${ }^{1,}{ }^{*}$ and D. Ebregbe ${ }^{2}$ \\ 1Electrical Department, Bayelsa State College of Arts \& Science (BYCAS) YenagoA, Bayelsa State NiGERIA \\ ${ }^{2}$ ELECTRICAL ENGINEERING DEPARTMENT, NigER DELTA UNIVERSITY, WILBERForCE ISLAND, BAYELSA STATE. NIGERIA \\ E-mail addresses.1ebiyabefa@yahoo.com,2 debregbe@yahoo.co.uk
}

\begin{abstract}
The global population is rapidly increasing, requiring more road transportation vehicles: increasing the demand on oil for the production and fueling of these vehicles, with challenges of oil production shortage due to increased pipeline vandalism, and issues of climate change and global warming as a result of tailpipe emissions from internal combustion engine (ICE). The mass production of the hybrid electric (HE) and the electric vehicle (EV) is still awaited due to subsystem inefficiencies. Increasing the efficiencies of the power converters within subsystems of these HEVs and EVs will increase the performance of the new transportation vehicles. This paper presents the development of DCM based buck converter and its applications in the HEVs/EVs using the MatLab/Simulink Simulation Platform. The paper also highlights the implications of implementing a single stage buck converter, and the merits of adopting multilevel converters in achieving the 300mV output ripple voltage, ensuring equal current distribution among interleaved switching devices for the passenger vehicle.
\end{abstract}

Keywords: Buck Converter, PWM, EVs, HEVs, Multilevel, MatLab/Simulink.

\section{INTRODUCTION}

The electrical low voltage load requirement in the passenger vehicle is increasing exponentially due to customers demand on increased safety, vehicle reliability, luxury, and comfort [1]. The global population is increasing rapidly, requiring more road transportation vehicles for mobility, increasing the demand on oil for the production and fuelling of these vehicles, with the challenges of limited oil reserves, evident energy depletion [2], and vehicle tailpipe emissions. Unfortunately, environmental pollution and safety problems contributed by the increased energy consumption are recently the dominant issues not only in the press, but in our society. The burning of fossil fuel emits $\mathrm{CO} 2, \mathrm{SO} 2 \mathrm{NOx}$ and $\mathrm{CO}$, and these gases create environmental pollution problems such as global warming, climate change and urban pollution [3] which can be prevented by the widespread use of EVs. The gasoline powered vehicles are responsible for urban pollutions, accounting for $57 \%$ of nitrogen oxides emissions, and $82 \%$ of carbon monoxides (CO) [4]. And recently, precisely January 1, 2016, the Indian government placed an order restricting the movement of vehicles in the cities as a response to urban pollution. Vehicles with even plate numbers are to use the roads on even days within the week, while vehicles with odd plate numbers are to use the roads on odd days.

An effort to handling the challenge of the increasing electrical load, minimizing vehicle fuel consumption, and to reduce tailpipe emission led to the investigation of a dual-voltage architecture for the passenger vehicle by the automotive industry [5]. The dual voltage architecture with a very significant benefit of electronics switching that provides new safety, convenience and comfort functionality in the car makes use of $14 \mathrm{~V}$ and $42 \mathrm{~V}$ voltage sources. The $14 \mathrm{~V}$ source serves the low voltage electrical loads such as; wiper motors, mirror motors, break lights, parking lights, etc, and the $42 \mathrm{~V}$ source serves the high voltage electrical loads.

In September 1993, the President of the United Sates and the general managers of the big three automakers (GM, Ford and Chrysler) declared the program of Partnership for Next Generation Vehicles (PNGV) to produce vehicles of high efficiencies. 


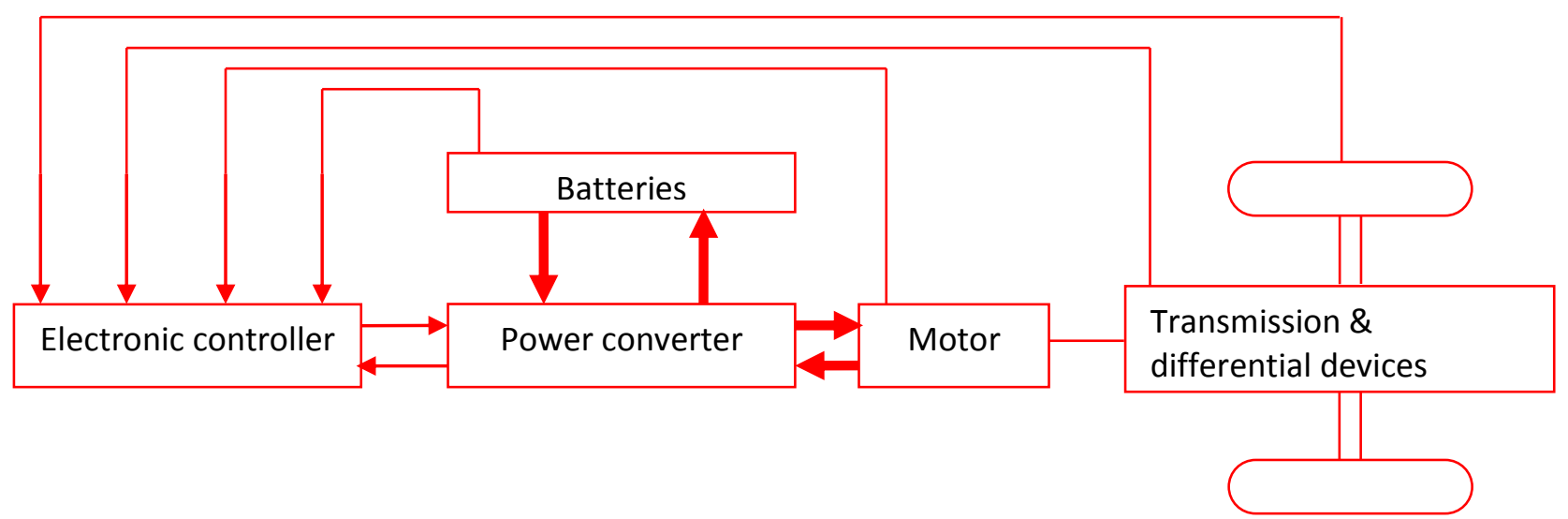

Figure 1: Functional block diagram of EV propulsion system [4]

This followed the 1990 California rules that mandated the production of $10 \%$ of all vehicles with zero emission by 2004. The PNGV program agreed on reduced energy demand by $50 \%$, improving fuel consumption by $55 \%$, reducing power train and transmission losses by one-third, and recovery of between $50 \%$ to $70 \%$ of braking energy [6].

Although the electric and hybrid electric vehicles have been commercially available, they are unaccepted, and lack patronage by customers due to cost and performance. These vehicles needs increased subsystems efficiencies to let them perform absolutely as their ICE vehicles counterpart in such performance parameters as; driving range, reliability, temperature management, and charging time: as all subsystems within the HEVs and EVs have a power converter specifically designed for efficient system performance. Among the several converters, is the buck converter for stepping down high voltage from the fluctuating dc bus to a low voltage to serve the low voltage electrical loads in the vehicle, and if designed appropriately, can contribute to the increased system performance of these intelligent vehicles. This paper presents a $42 \mathrm{~V} / 14 \mathrm{~V}, 1 \mathrm{~kW}$ multilevel DC-DC buck converter architecture simulations using the MatLab/Simulink simulation platform. The developed system model is used to thoroughly investigate the transient and steady-state characteristics of the electrical loads in the HEVs/EVs.

\section{HEVs AND EVs ELECTRONICS}

Power electronics is one of the major players in the fields of engineering, propelling the transformation of the automotive industry from the ICE powered vehicles into the clean transportation system, with the development of the HEVs, EVs, and the fuel cell powered vehicle. Figure1 shows the functional block diagram of a typical EV propulsion system, with the thick and thin lines representing the power and signal flows respectively.

The auxiliary electrical devices such as wipers, lamps and mirror motors in the vehicle are basically operated at a lower voltage: typically $14 \mathrm{~V}$. The $14 \mathrm{~V}$ low voltage is generated from the high voltage (HV) bus of the EV battery [7].

\subsection{Automotive Power Converters}

Power circuit used for the HEVs and the EVs are primarily to provide efficient energy conversion, and uses only lossless circuit elements that are either fully ON or OFF, such as IGBTs, MOSFET, etc, together with Inductors and Capacitors [8]. Although there are current fed and voltage fed power converters for the HEV and EV applications, the voltage fed converters are used mostly because they are simple in construction, and have bidirectional power for both motoring and regeneration [9].

In serving the low voltage electrical loads for the HEV and $\mathrm{EV}$, it is always desired to convert a dc voltage source of very high magnitude $V_{S}$ to a dc voltage source of very low magnitude $V_{o}$, as shown in Figure 2 . This dramatic voltage stepping down operation is made possible with the use of the DC-DC buck converter.

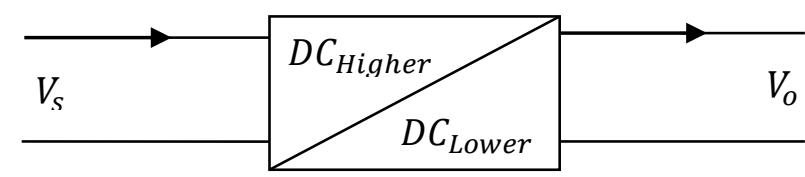

Figure 2: Voltage regulator

\subsection{Buck Modes of Operation}

The buck converter can be operated in two modes: the continuous conduction mode (CCM), and the discontinuous conduction mode (DCM). The CCM 
mode of operation is characterized with a non-zero inductor current as shown in Figure 3. This non-zero inductor current has great disadvantages in the HEV and EV applications in such performance parameters as energy management, safety, and electrical components sizing.

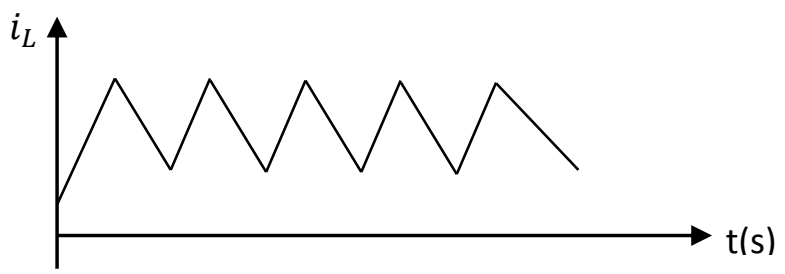

Figure 3: CCM mode of buck converter operation

Operating the buck converter in the DCM mode offers very critically important characteristics, typically important for the HEV and EV applications. As can be seen in Figure 4, the turn-on current of the buck converter in the DCM mode is typically zero, and as a result, reducing the turn on loss to zero, and consequently increasing the system performance.

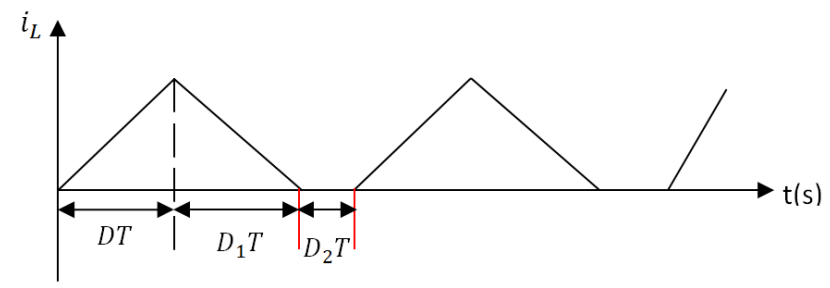

Figure 4: Discontinuous conduction mode of buck converter operations

The point of operation of the buck converter where the converter switches from the undesired CCM mode to the desired DCM mode is the boundary, or critical point. For typical mathematical development of the buck converter, the critical condition of the buck converter is considered the point where the converter inductor current is set to zero.

\subsection{DCM Buck Converter Modelling and Components Selection.}

A system model is a set of mathematical equations representing a typical physical system, though in most cases, the mathematical models hardly represent the physical system efficiently due to some mathematical inaccuracies. The mathematical representations of physical systems are obtained using the Laplace transforms in terms of differential equations, and the use of the transfer function method. The transfer function method of developing the system model is most often preferred as there are already existing connecting equations between known transfer function models and typical physical system behaviours.

The switching frequency of switching devices used in the HEVs and EVs ranges up to $200 \mathrm{kHz}$, but a lesser value of $100 \mathrm{kHz}$ is used for practical implementations in the automotive industry. Although high switching losses and thermal run away are attributes of high frequency operations using conventional switching devices, the HEVs and EVs are intended for high efficiencies, and makes use of the advances in the power electronics industry. Such advances includes: improved devices, microcomputer-based high performance control using expert system, fuzzy control, and neural networks [10]. The introduction of resonant converters [11] and high-Q- factor snubber networks in alleviating the device switching losses improved the performance of high frequency applications. The silicon carbide ( $\mathrm{SiC}$ ) switching devices for automotive applications [18 - 21] in [1] with operating temperatures up to $650^{\circ} \mathrm{C}$ has further improved the performance of the high frequency operations of the power devices.

In designing the buck converter, the size of the inductor (L) which is frequency dependent is made much lower to reduce the weight of the buck converter module, and the capacitor (C) is selected to reduce the variations in the output of the buck converter to obtain the $300 \mathrm{mV}$ standard specified by the automotive industry.

A buck converter designed for the HEV and EV applications should operate in the DCM mode, as the DCM mode of operation has several advantages over the CCM mode, which includes among others; reduced output voltage ripples, the reduced inductance value, and zero turn-on loss.

The value of the inductance which will ensure the buck converter operating in the DCM mode is as expressed in equation (1).

$$
\mathrm{L}_{\min }=\frac{0.47 \mathrm{R}_{\min }}{2 \mathrm{f}}
$$

In (1), $L_{\min }$ is the minimum inductance in Henry, $R_{\min }$ is the minimum load resistance in Ohms and $f$ is the switching frequency.

The value of the capacitance ensuring the minimum output voltage ripple is always related to the inductance inversely [6] in buck converter applications and is expressed as;

$$
\mathrm{C}=\frac{\mathrm{V}_{\mathrm{o}}}{8 \Delta \mathrm{V}_{\mathrm{o}} \mathrm{L}_{\text {min }} \mathrm{f}^{2}}(1-\mathrm{D})
$$


In (2), $V_{o}$ is the output voltage, $\Delta \mathrm{V}_{\mathrm{o}}$ is the output voltage ripple, $\mathrm{D}$ is the duty cycle and $\mathrm{C}$ is the capacitance in Farad.

\subsection{Output Voltage Ripples Calculation}

Every electronic component used in the design of electronic circuits to some extent has some imperfections. And these imperfections contribute to the imperfect system performance of real system design. Although a more involved mathematical analysis can be performed to produce a very efficient mathematical expression for the output voltage ripple of the buck converter, a more quick mathematical formulation method of the output ripple voltage is preferred, more useful [12], and functional than the rather involved mathematical analysis.

From Figure 5, the minimum value of the inductive current can be estimated as;

$$
\mathrm{I}_{\min }=\mathrm{I}_{\mathrm{o}}-\frac{\Delta \mathrm{i}_{\mathrm{L}}}{2}
$$

In (3), $I_{\min }$ is the minimum inductor current, $I_{o}$ is the load current and $\Delta_{\mathrm{iL}}$ is the inductive ripple current.

But, considering the load connected,

$$
\mathrm{I}_{\mathrm{o}}=\frac{\mathrm{V}_{\mathrm{o}}}{\mathrm{R}_{\mathrm{L}}} \text {, and } \Delta \mathrm{i}_{\mathrm{L}}=\frac{\mathrm{V}_{\mathrm{o}}(1-\mathrm{D})}{2 \mathrm{Lf}}
$$

Substituting (4) into (3), the minimum inductor current becomes

$$
I_{\min }=V_{\mathrm{o}}\left[\frac{1}{\mathrm{R}_{\mathrm{L}}}-\frac{(1-\mathrm{D})}{2 \mathrm{fL}}\right]
$$

In order to operate the buck converter in the DCM mode, the minimum inductive current in equation (5) is equated to zero as expressed in equation (6) as

$$
\mathrm{V}_{\mathrm{o}}\left[\frac{1}{\mathrm{R}_{\mathrm{L}}}-\frac{(1-\mathrm{D})}{2 \mathrm{fL}}\right]=0
$$

Equation (6) is a product of two expressions equated to zero, with one of the expressions been the output voltage $\left(\mathrm{V}_{0}\right)$. The buck converter as said earlier is a power source intended to provide constant output voltage to the low voltage electrical loads in the HEVs and EVs, and therefore the output voltage $V_{o}$ cannot be zero. So, from a mathematical point of view, equation (7) is obtained.

$$
\frac{1}{\mathrm{R}_{\mathrm{L}}}-\frac{(1-\mathrm{D})}{2 \mathrm{fL}}=0
$$

Making $L$ the subject of formula from equation (7)

$$
\mathrm{L}_{\mathrm{c}}=\frac{(1-\mathrm{D}) \mathrm{R}_{\mathrm{L}}}{2 \mathrm{f}}
$$

Where $L_{c}$ is the value of the critical inductance

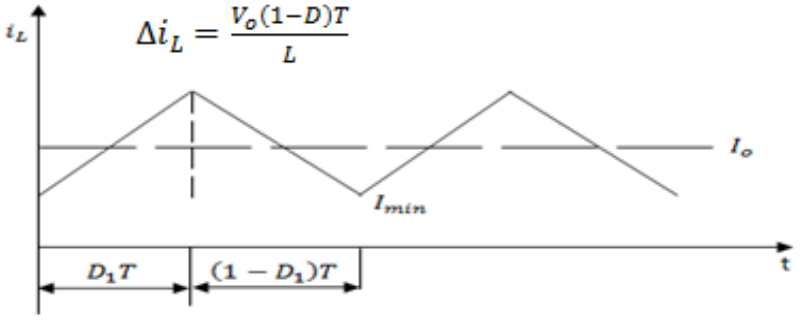

Figure 5: Buck converter inductive current

The capacitive ripple current in the buck converter is shown in Figure 6. In the design of any buck converter for automotive applications, and to meet global best practice, it should be the desire of the designer that all the current ripples in the inductor flows through the output capacitor, and therefore, should be far more in magnitude than the ripples in the load current [13]. That is;

$$
\Delta \mathrm{i}_{\mathrm{L}} \gg \Delta \mathrm{I}_{\mathrm{o}}=\frac{\Delta \mathrm{V}_{\mathrm{o}}}{\mathrm{R}_{\mathrm{L}}}
$$

One of the very important equations used in the analysis of a buck converter is equation (10).

$$
\Delta \mathrm{i}_{\mathrm{C}}=\Delta \mathrm{i}_{\mathrm{L}}-\Delta \mathrm{I}_{\mathrm{o}}
$$

Equation (11) is obtained by substituting (9) into (10).

$$
\Delta \mathrm{i}_{\mathrm{C}} \approx \Delta \mathrm{i}_{\mathrm{L}}
$$

The magnitude of the voltage ripples contained in the output of the buck converter can be estimated by using the relationship as expressed in equation (12).

$$
\mathrm{Q}=\mathrm{CV}_{\mathrm{o}}
$$

In (12), $Q$ is the charge stored in the capacitor, $C$ is the Capacitance of the capacitor and $V_{o}$ is the voltage across the output capacitor.

From Figure 6, the change in charge $(\Delta Q)$ in the capacitor is the area of the triangle, and applying the area of a triangle formula expressed in equation (13), and substituting into equation (12) produce equation (14).

$$
\begin{aligned}
& \text { area of triangle } \left.=\frac{1}{2} \text { [base } \times \text { height }\right] \\
& \Delta \mathrm{Q}=\frac{1}{2}\left[\frac{\mathrm{T}}{2}\right] \times\left[\frac{\Delta \mathrm{i}_{\mathrm{L}}}{2}\right]
\end{aligned}
$$

Equation (12) can also be expressed as;

$$
\Delta \mathrm{V}_{\mathrm{o}}=\frac{\Delta \mathrm{Q}}{\mathrm{C}}
$$

Here, $\Delta V_{0}$ is the output ripple voltage of the buck converter, $\Delta Q$ is the change in charge stored in the capacitor and $\mathrm{C}$ is the Capacitance of the capacitor. Substituting the inductive current ripple expression in equation (4) into equation (14), and substituting the change in charge expression obtained from equation (14) into equation (15), the output voltage ripple satisfying the automotive industries specification is obtained and is expressed as;

Vol. 35, No. 2, April 2016 


$$
\Delta \mathrm{V}_{\mathrm{o}}=\frac{\mathrm{V}_{\mathrm{o}}(1-\mathrm{D})}{8 \mathrm{LCf}^{2}}
$$

The output voltage ripple can vary between 0.2 Volts and 0.5 Volts, though most often a typical value of $1 \%$ of the output voltage is recommended [14].

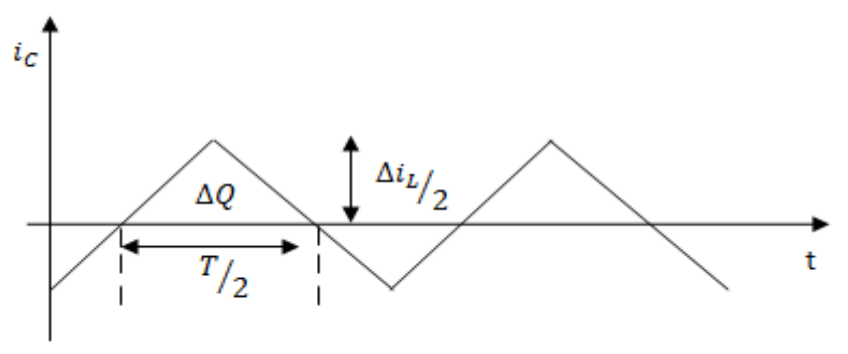

Figure 6: Buck converter capacitive current

Applying the increased capacitance value and the reduced inductance value obtained for the DCM buck converter, the specified output ripple voltage by the automotive industry as shown in Table 1, can always be achieved using the appropriate control technique.

\section{Table 1: 42V/14V Automotive Design Specifications}

\begin{tabular}{lcc}
\hline \multicolumn{1}{c}{ Parameter } & symbol & Value \\
\hline Input voltage & $\mathrm{V}_{\mathrm{s}}$ & 42 \\
Output voltage & $\mathrm{V}_{\mathrm{o}}$ & 14 \\
Rated output power & $\mathrm{P}_{\mathrm{o}}$ & $1 \mathrm{~kW}$ \\
Output ripple voltage & $\Delta V_{o}$ & $300 \mathrm{mV}$ \\
Output ripple current & $\Delta I_{o}$ & $1 \mathrm{~A}$ \\
\hline
\end{tabular}

The single phase inductive current of the buck converter which varies between zero (0) and one forty (140A) Amperes is as shown in Figure 7: with inductance of $(0.47 \mu \mathrm{H})$ and capacitance of $(1.81 \mathrm{mF})$.

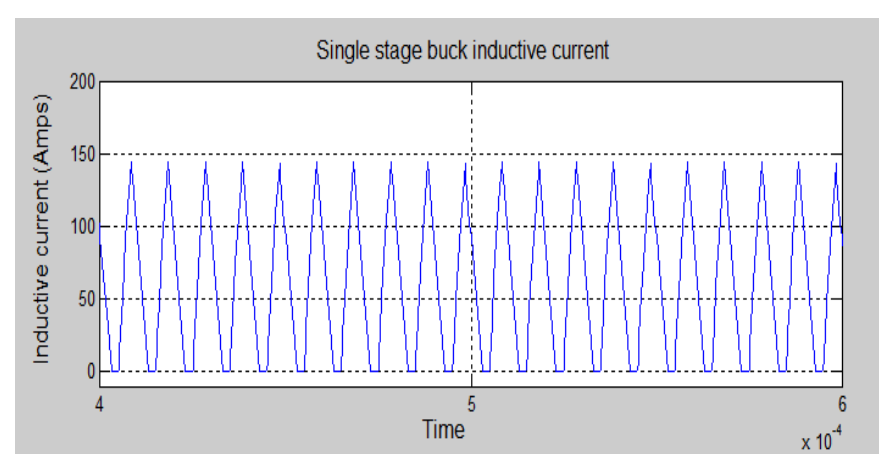

Figure 7: Inductive current of a single phase buck converter

\section{MULTILEVEL BUCK CONVERTER}

In the present HEVs and EVs, the electric load is considerably high, and therefore requires a very high load current serving the vehicle electric load. This high current passes through the switching device during the on time of the switch, and with the $14 \mathrm{~V}$ voltage system for the passenger vehicle, the load current expected to pass through the single switching device can be as high as $71.43 \mathrm{~A}$ for a $1 \mathrm{~kW}$ rated load. This is practically unimplementable on a single switching device.

Paralleling of switching devices is an option in the reduction of the inductive current that has to pass through the switches. Several switching devices are connected in parallel in this method [15], sharing the total inductive current among the number of switches equally, by a method of time distributed conduction. The shared current conduction of each phase is made realizable by the introduction of the phase shifts. Though the buck converter is operated in the discontinuous conduction mode (DCM), the output current is continuous: as the output current is the summation of the individual phase currents.

Operating the buck converter with parallel switching devices (multilevel) reduces the stress in the switches, and in extension, increases the reliability of the switching devices [16], which has an increased effect on the safety of the driver and the passenger in the vehicle. Among other advantages is the zero turn-on loss in the switching devices, as the buck converter operated in the DCM mode always have a zero turn-on current $[17,18]$.

\section{TIMING}

Timing of the switching devices is a major challenge in operating the buck converter in multilevel. The issue of timing; if not properly handled, can result in the damaging of the switching devices. The time has to be correctly share among the number of switches without internal interference to ensure that each of the switches only conduct for the stipulated 360/N microseconds, where $\mathrm{N}$ is the number of parallel connected switches.

In the multilevel buck converter, the inductive current is shared equally among the five (5) switching devices connected in parallel. With a total period of $10 \mu$ secs (100 kHz operating frequency), the gating signals are time delayed by $2 \mu$ secs from each other: and the switching OFF of the last phase switching device begins the switching $\mathrm{ON}$ of the first phase switching device as shown in Figure 8. Though the switching devices conduct at different time intervals and operate in the DCM mode, as mentioned earlier: the output (load) current is continuous, and it is as shown in Figure 9. 

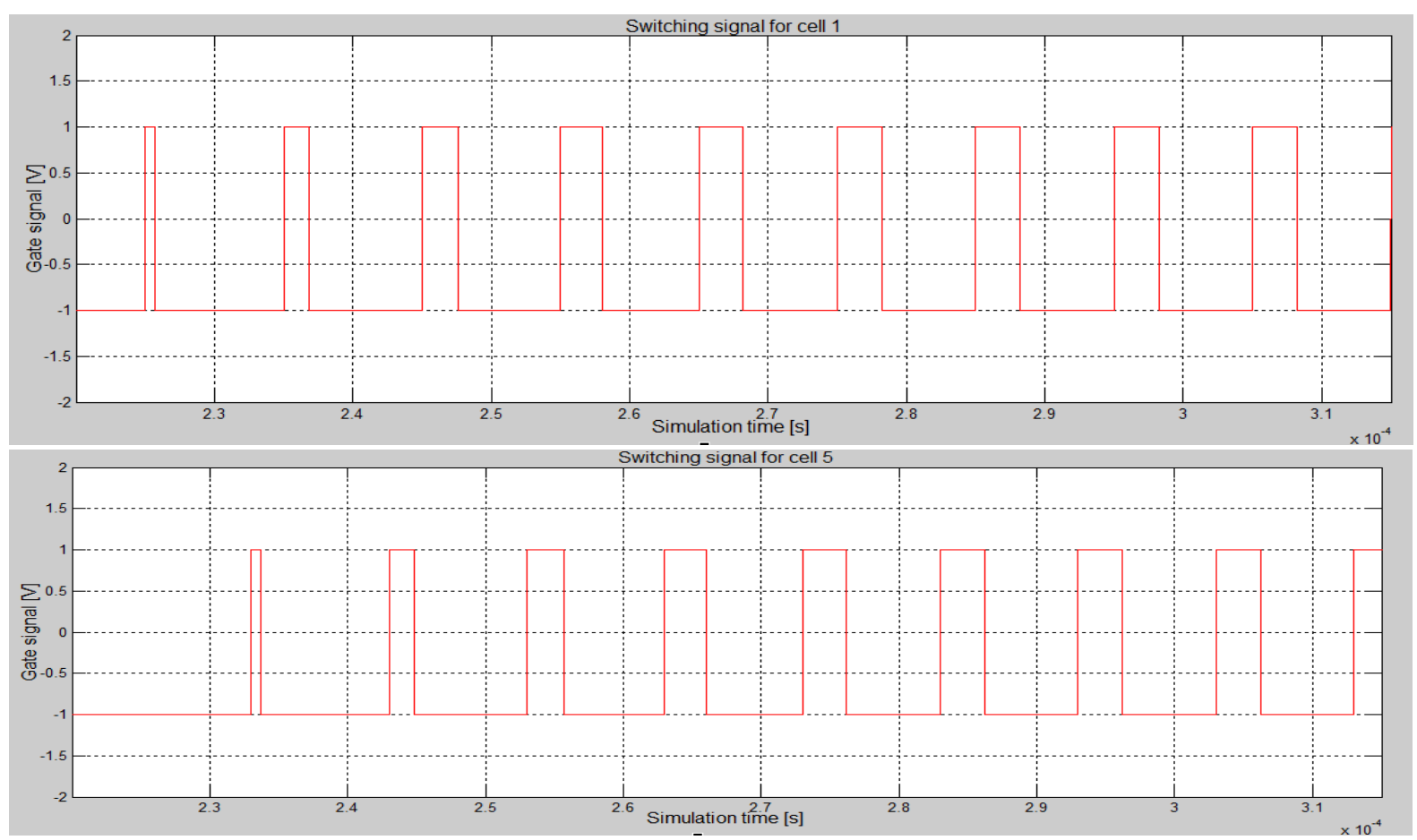

Figure 8: Switching mechanism for 5 phases buck converter

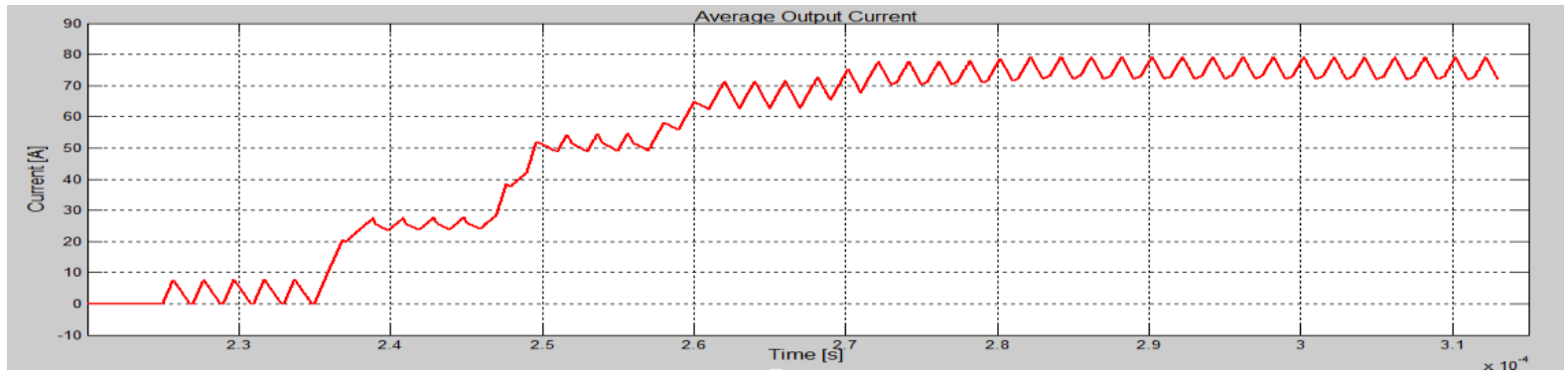

Figure 9: Load current of the Multilevel buck converter

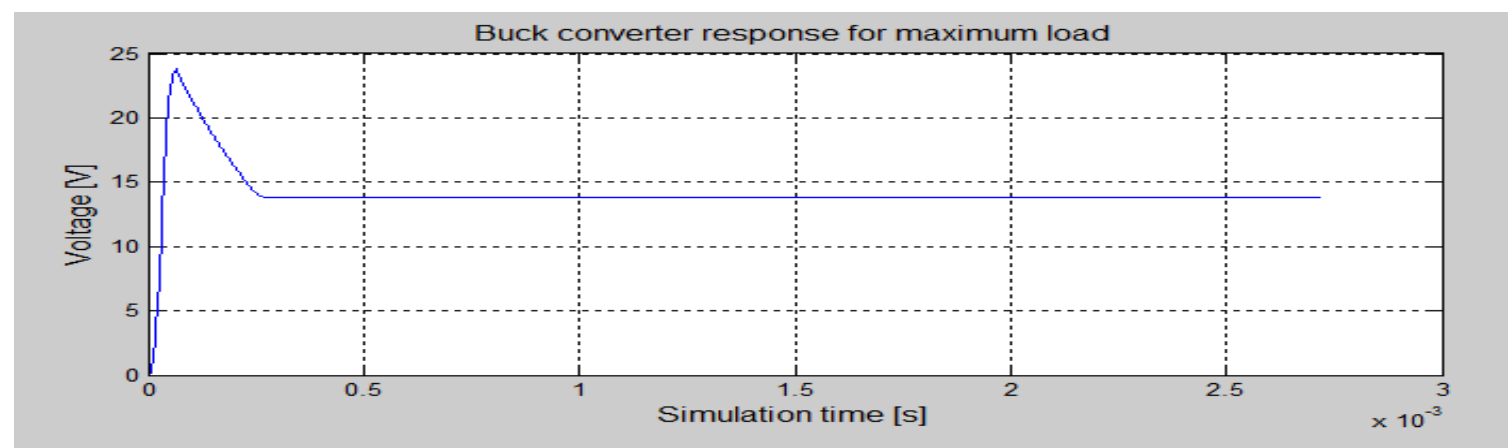

Figure 10: Systems response for maximum electrical load

Designing a multilevel buck converter of $\mathrm{N}$ cells definitely increases the cost approximately $\mathrm{N}$ times, compared to a single phase buck converter. But, automotive application where safety has the highest priority, multilevel converter is an option in reducing the stress on the switching devices. The HEV and EV design engineers prefer multilevel buck converter to single switching device buck converter irrespective of the perceived costs of finance and time. Further, major advances have been made in the research of semiconductor devices, providing an opportunity for the development of multilevel buck converter modules, increasing reliability, at a reduced production cost.

\section{PULSE WIDTH MODULATED (PWM) FEEDBACK}

The low voltage electric loads needs some form of constant output voltage within the permitted boundaries as specified, regardless of the variations in the load, or the input voltage. Applying the 
maximum electrical load on the buck converter produces the voltage response as shown in Figure 10. A proper control technique is employed to produce the desired system performance, as overshoots as can be seen in Figure 10 is undesired in control system design. In order to obtain the desired system response, a standard $2^{\text {nd }}$ order transfer function was developed using equations (17) and (18) [19].

$$
\begin{aligned}
& \% \text { overshoot }=\mathrm{e}^{-\zeta \pi \sqrt{1-\zeta^{2}}} \times 100 \\
& \mathrm{t}_{\mathrm{s}}=\frac{4}{\zeta \omega_{\mathrm{n}}}
\end{aligned}
$$

While the transfer function of the open loop system is as shown in equation (19), the transfer function for the PID controller is as shown in equation (20).

$$
\begin{aligned}
G(s) & =\frac{10656660007.21}{s^{2}+66667 s+10656660007.21} \\
G_{c}(s) & =\frac{2.9667111 s^{2}+30971.549 s+402403464.6}{s^{2}+88351.43 s}
\end{aligned}
$$

In sustaining the constant output voltage, a connection between the output of the buck and the gating signals of the switching devices are established. A pulse width modulated (PWM) feedback is applied, in adaptively adjusting the duty cycle of the switches to maintain the required output voltage. The duty cycle is used as the gate signal to drive the switching devices, thereby satisfying the requirement of the changing electric load in the vehicle. The switching devices conduct at the instance when the saw tooth signal within the internal PWM mechanism is less than the incoming error control voltage.

\section{SIMULATION RESULTS}

The MatLab/Simukink Simulation Platform was used in the simulation of the complete five cells DCM buck converter. The lighting and heating electrical loads of the HEVs and EVs were used for the simulation.

\subsection{HEV and EV Heating Load}

Heating components in the HEVs and EVs are generally non-inductive [20], but resistive and modeled as such during the simulations. Though the heating current required in the passenger vehicle considering all the heating elements is about 79.29A, a value of $61.428 \mathrm{~A}$ was used considering the automotive industry's specification for the $42 \mathrm{~V} / 14 \mathrm{~V}$ architecture as shown earlier in Table 1.

The peak inductive current of about $150 \mathrm{~A}$ is too high for a single switching device as shown in Figure 11, and therefore needed some form of reduction using the multilevel. The waveform of the current that passes through a phase in the multilevel buck converter is shown in Figure 12.

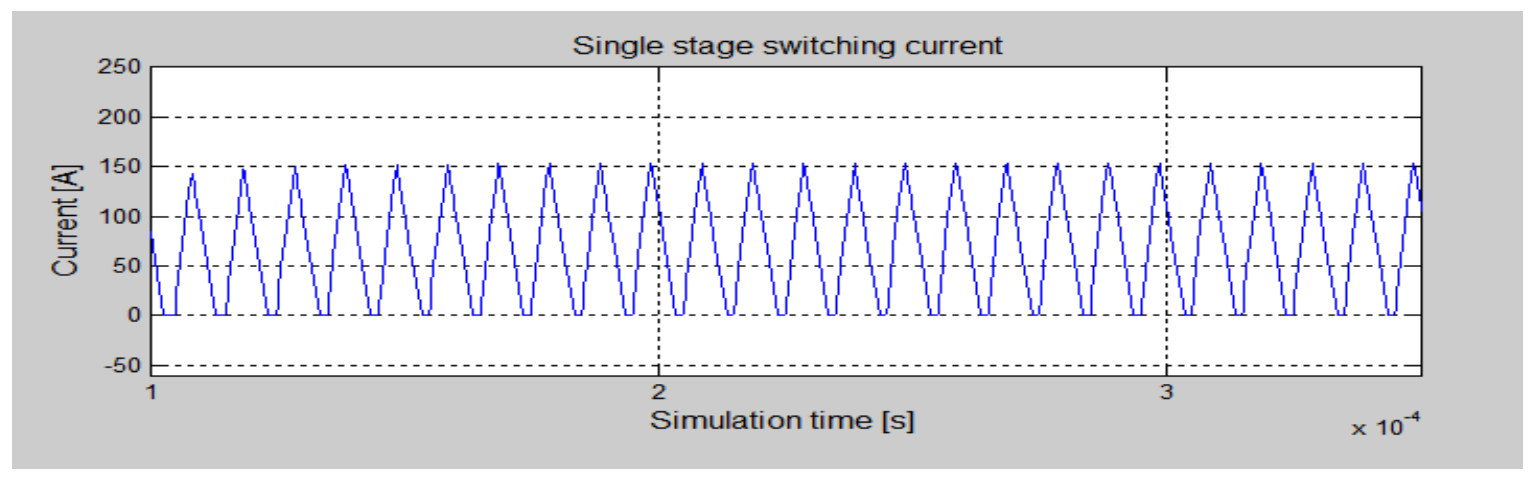

Figure 11: Heating electrical load current

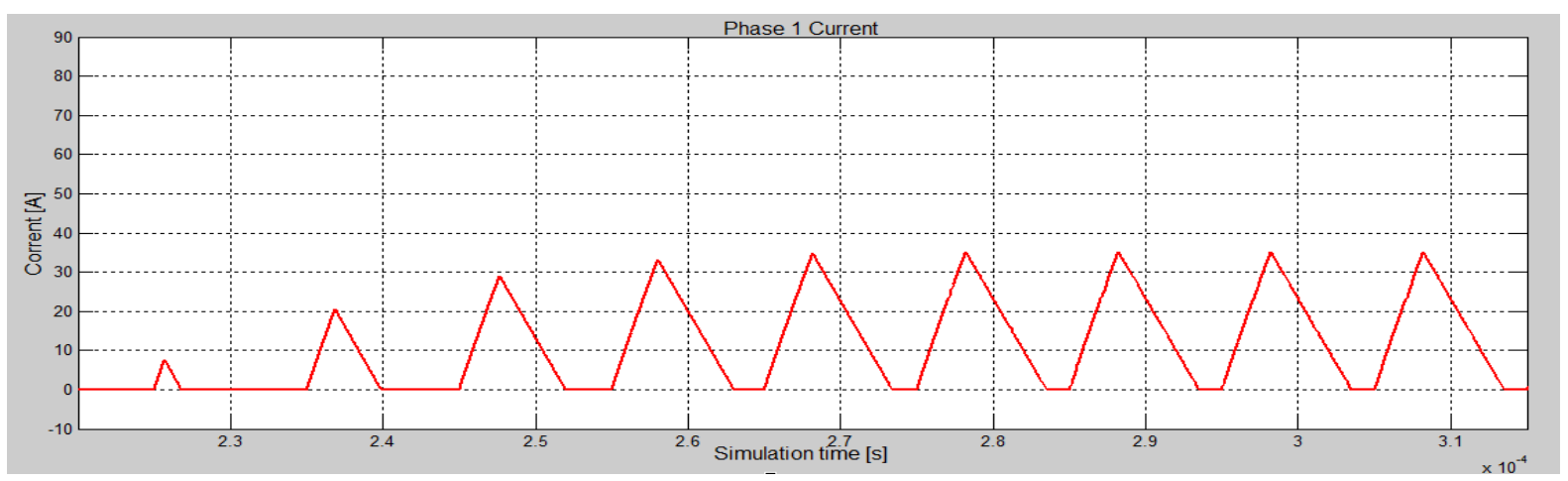

Figure 12: A phase current in the multilevel DCM buck converter 


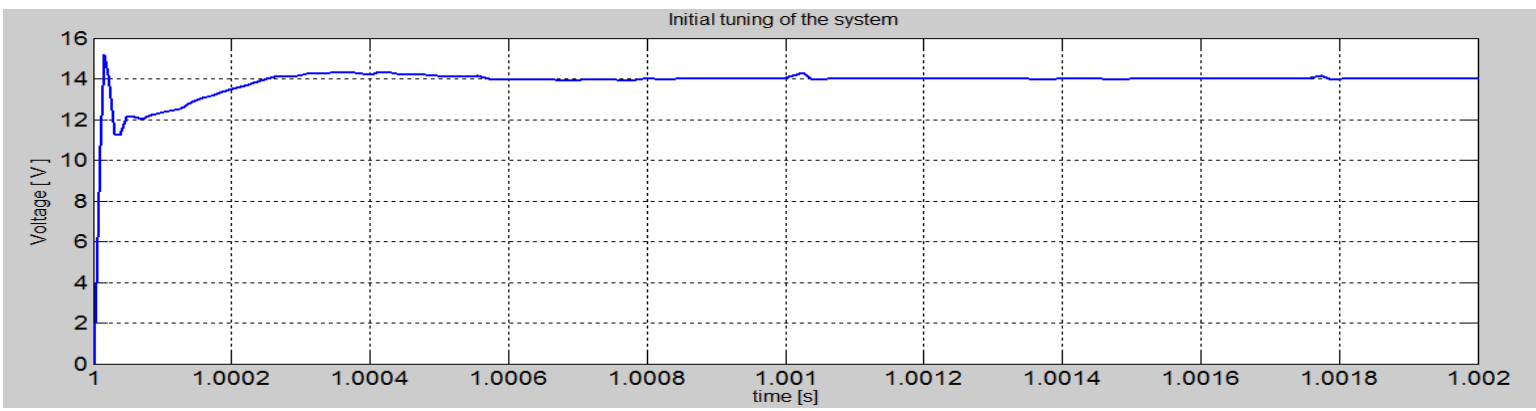

Figure 13 (a): Voltage response of multilevel buck converter

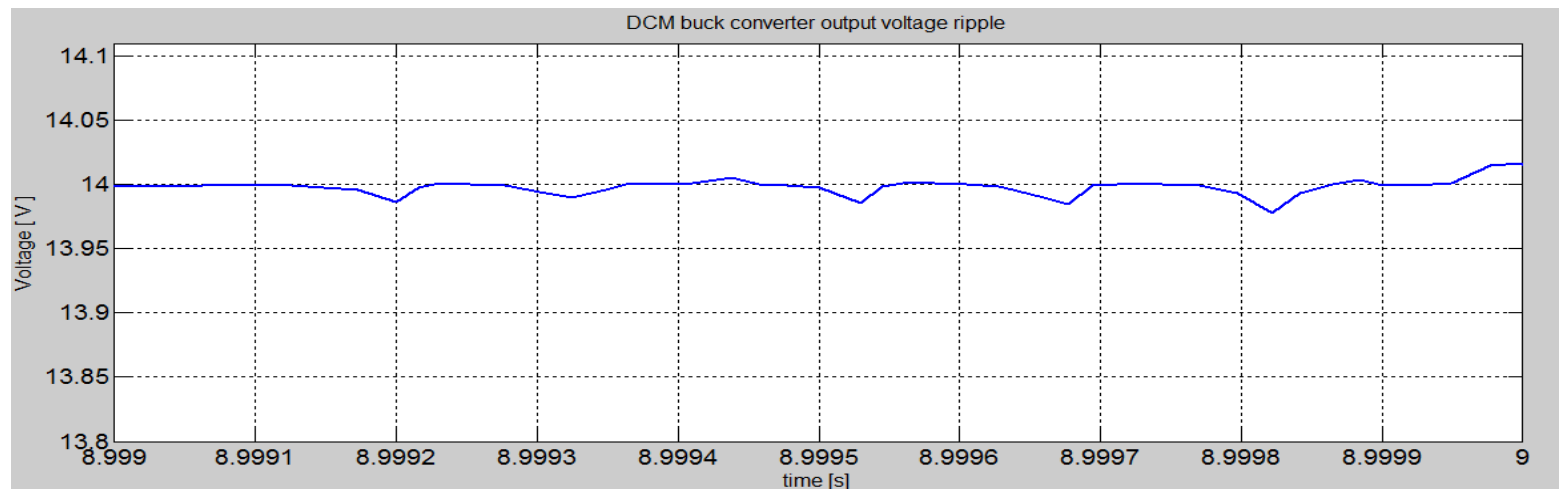

Figure 13 (b): Output voltage ripple

In Figure 12, it is clear that the steady state inductive current which passes through each switch obtained for the same vehicle heating electrical load using the multilevel buck converter is about $30 \mathrm{~A}$, instead of the detrimental $150 \mathrm{~A}$ for the single switch. The $30 \mathrm{Amps}$ which is small enough considering the passenger vehicle electrical load can be considerably handled by the automotive power switches.

\subsection{HEV and EV Lighting Loads}

The lamps for HEVs and EVs are also classified by the automotive manufacturers to be non-inductive, but resistive. Since the total lamp load in the passenger vehicle is estimated at about $15.57 \mathrm{~A}$, with $14 \mathrm{~V}$ at the converter output, a resistive load of $0.899 \Omega$ is obtained and used for the simulations. The simulated output voltage response with tuning is shown in Figure 13 (a), while the output voltage ripples is shown in Figure 13 (b)

\section{CONCLUSION}

In this paper, a five cells DCM multilevel dc-dc buck converter for HEVs and EVs is developed and implemented in MatLab/Simulink. The simulation results of the multilevel buck converter conforms with the $300 \mathrm{mV}$ output ripple voltage specification for the $42 / 14 \mathrm{~V}$ system. The inductive current is shared among the switching devices in the multilevel converter, with the added advantage of the zero turn- on loss of these devices. Making useful use of the advances in semiconductor devices, such as the development of Silicon Carbide (SiC) switching devices for very high temperature applications, the multilevel buck converter if implemented with these SiC switches could be very promising for the $14 / 42 \mathrm{~V}$ system, and could also contribute to the desired increased system performance of the HEVs and EVs. In terms of safety and reliability, snubber networks and zero switching-loss technologies can be incorporated to protect the switching devices of the multilevel buck converter; as such snubbers and improved resonant networks perform admirably in alleviating switching losses of switching devices.

\section{REFERENCES}

[1] Kassalian, J. G., and Perreault, D. J "The Future of Electronics in Automobiles" Proceedings of 2001 International Symposium on power semiconductor Devices \& ICs, Osaka.

[2] Roth, L. R “ Long term global energy issues in Industrial Plasma Engineering" Institute of Physics Publications, vol. 1, 1995.

[3] Bose, B.K "Energy, Environment, and Advances in Power Electronics" IEEE Transactions on Power Electronics, Vol. 15, No. 4, July, 2000.

[4] Chan, C. C, and Chau, K.T "An overview of power electronics in electric vehicles" IEEE Transactions on Industrial Electronics, 1997, vol. 44, No. 1, pp. 313.

Vol. 35, No. 2, April 2016 
[5] Kassakian, J. G., Wolf, H.C., Miller, J. M., and Hurton, C. J "Automotive electrical systems circa 2005" IEEE Spectrum, August 1996, pp. 22-27.

[6] Ogden, J., and Steinbugler, M "Notes on the meeting: "The Fuel Cell for the Next Generation of Vehicles" Vice President Gore's Automotive Technology Symposium \#2, July, 1994.

[7] Mi, C and Zhang, X "Vehicle power management: modelling, control and optimization" London, Springer, (2011).

[8] Shrud, M. A., Bousbaine, A., Ashur A. S., and Thorn R., " $42 \mathrm{~V}$ power system architecture development. $3^{\text {rd }}$ IET Conference on Automotive Electronics, Warwick UK 28-29 June, 2007, pp. 1-17.

[9] Chan C., and Chau K. T "Modern electric vehicle technology" Oxford University Press, New York (2001).

[10] Bose, B. K "Recent Advances in Power Electronics" IEEE Transactions on Power Electronics, Vol. 7, No. 1, January, 1992.

[11] Divan, D. M “The Resonant DC Link Converter- A New Concept in Static Power Conversion" IEEE Transactions on Industrial Applications, Vol. 25, No. 2, March, 1989

[12] Choi, B "Pulsewidth modulated dc-dc power conversion: circuits, dynamics and control' John Wiley\& Sons, Hoboken, New Jersey: (2013).

[13] Mohan, N., Undeland T. M., and Robins, W. P "Power electronics: converters, applications and design," John Wiley \& Sons, Inc., United States: (1995).
[14] Husain, I Electric and Hybrid Vehicles: Design Fundamentals, $2^{\text {nd }}$ edition. CRC Press, Boca Raton (2011)

[15] Altes, J. M., Dolcet, E.G., and Solorzano, B.P “Analysis of the Most Appropriate Electrical Architecture and Communication Bus for the New Dual Voltage 42/14V System" IECON-2002: Proceedings of the 2002 28th Annual Conference of the IEEE Industrial Electronics Society, Vol.1-4 ,pp. 1687-1692, (2002).

[16] Timothy, C. Neugebauer and David J. Perreault "Computer aided optimization of DC/DC converters for automotive applications," IEEE Transactions on Power Electronics.Vol.18., No.3, May, (2003).

[17] Khan, L. A "DC-to-DC Converters for Electric and Hybrid Vehicles" Proceedings of IEEE Workshop on Power Electronics in Transportations, Record, pp.113-122, (1994)

[18] Nicastri, P., and Huang, H "42V Power Net: providing the vehicle electrical power for the 21st century" Presented at the SAE Future Transportation Technology Conf. Expo., Costa Mesa, CA, Aug. (2000).

[19] Philips, C. L., and Parr, J. M "Feedback control systems" 5th edition, United States: Pearson Education, Inc., (2011)

[20] Silvus, H. S., and White, R. E "Inductances of automotive electromagnetic devices," Proceedings of the SAE 2002 world congress, in Detroit, Michigan, March 4-7, (2002). 